\title{
Reactions of Al-PTFE under Impact and Quasi-Static Compression
}

\author{
Bin Feng, Xiang Fang, Yu-chun Li, Shuang-zhang Wu, Yi-ming Mao, and Huai-xi Wang \\ College of Field Engineering, PLA University of Science and Technology, Hou Biaoying Road No. 88, Nanjing, \\ Jiangsu 210007, China \\ Correspondence should be addressed to Xiang Fang; 359449629@qq.com
}

Received 13 July 2015; Accepted 21 September 2015

Academic Editor: Ying Li

Copyright (c) 2015 Bin Feng et al. This is an open access article distributed under the Creative Commons Attribution License, which permits unrestricted use, distribution, and reproduction in any medium, provided the original work is properly cited.

Conventionally, the Al-PTFE is thought to be inert under quasi-static or static loads. However, here we reported an initiation phenomenon of Al-PTFE under quasi-static compression. Quasi-static tests suggest that reacted Al-PTFE samples had much higher toughness than unreacted samples. Dynamic test showed that the energy level needed to initiate the material was similar for quasistatic compression (88-100 J) and dynamic impact (77-91 J). The difference in density indicates that unreacted Al-PTFE has a higher crystallinity, which leads to the lower toughness. SEM images show numerous PTFE fibrils in unreacted composites which made the sample harder to crack and initiate.

\section{Introduction}

Reactive Materials (RMs) or impact-initiated materials have received much attention as a class of energetic materials in recent years. The mixture of $\mathrm{Al}$ and PTFE (polytetrafluoroethylene) is one of the most promising RMs and has been extensively studied. Al-PTFE composites have many possible uses in military and civilian fields as structural reactives for target damaging or propellant/explosive additives. When the material is impacted at speeds ranging from $200 \mathrm{~m} / \mathrm{s}$ to $5000 \mathrm{~m} / \mathrm{s}$, it first undergoes plastic deformation and flow or fracture process that causes intimate mixing of the constituents; then a diffusion controlled ignition takes place at heating rates ranging from $10^{4} \mathrm{~K} / \mathrm{s}$ to $10^{8} \mathrm{~K} / \mathrm{s}[1]$.

Ames [2] and Lee et al. [3] observed that large strain deformations, shear bands, and fractures formed during the impact play a significant role in the initiation of AlPTFE. Although Ames [4] did not express explicitly that it is a mechanochemical process, he believed that high temperatures generated in the impact were not sufficient to produce initiation. He also noticed that first signs of ignition are visible in the regions of high shear and regarded it as an evidence for a shear-induced combustion mechanism. On the other hand, some scholars consider the reaction as a thermochemical process. For example, Hunt et al. [1] believe that the mechanical load induces high stress and strain rates that transfer mechanical energy into thermal energy which promotes ignition. Zhang et al. [5] think the reaction initiation mechanisms are controlled by shock temperature rises.

Generally, the Al-PTFE is thought to be inert under quasistatic or static loads [4]. Interestingly, our recent experiments showed that Al-PTFE samples that went through a specific heat treatment could initiate under quasi-static compression.

\section{Experimental}

A preparation process including mixing, cold pressing, and sintering similar to that of Nielson et al.s [6] was adopted. The initial powders' average diameters are as follows: Al: 6-7 $\mu \mathrm{m}$ (JT-4, Hunan); PTFE: $25 \mu \mathrm{m}$ (3 M, Shanghai). All samples were fabricated with the same batch of purchased powders; therefore the characteristic differences between different batches of materials provided by the producer, which had been reported by Yarrington [7], were minimized.

$\mathrm{Al}$ and PTFE powders (26 wt\%/74 wt\%) were suspended in an ethanol solution and mixed by a motor-driven blender for 20 minutes and then were mixed by sonication for another 10 minutes to break up agglomerates. After the mixing, the wet mixture was put into a vacuum drying oven set at $50^{\circ} \mathrm{C}$ 


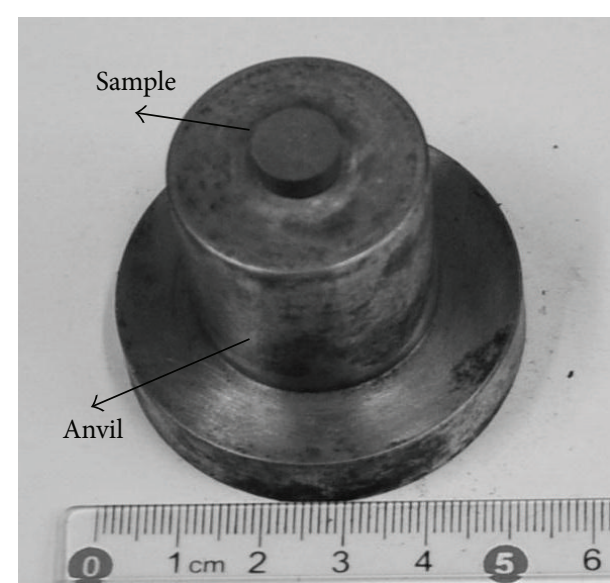

(a)

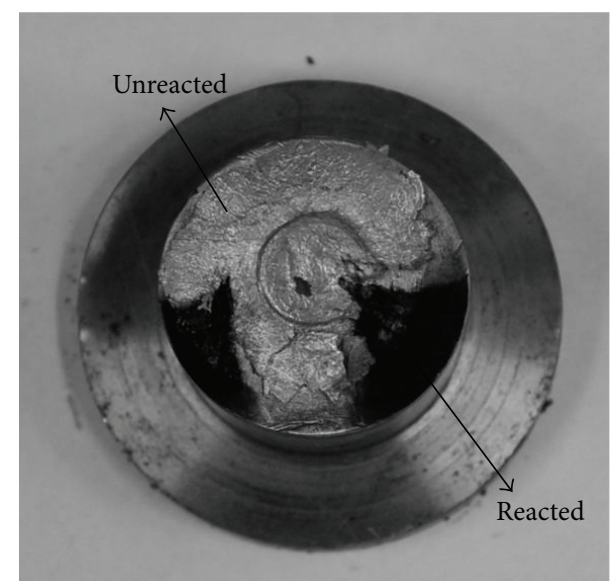

(c)

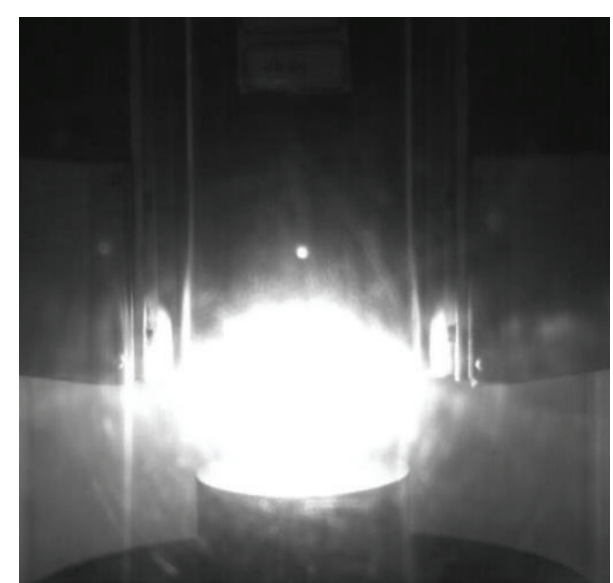

(b)

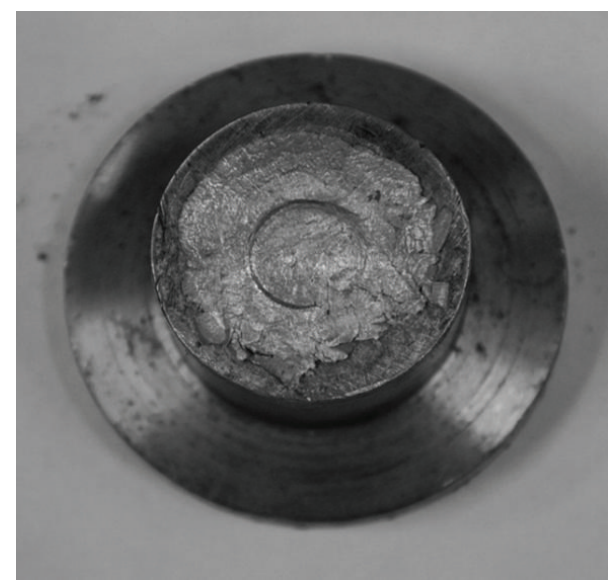

(d)

FIGURE 1: Impact-initiated reaction of Al-PTFE in drop-weight test. (a) Al-PTFE sample placed on the anvil before the drop-weight test. (b) Flame captured by high-speed photography in the test; (c) reacted Al-PTFE in the test; (d) unreacted Al-PTFE in the test.

for 48 hours. Then a screening stage was introduced where agglomerates were pressed through 80 -mesh screen by hand, which increases homogeneity of powder in the pressing stage. The molding pressure ranged from $72 \mathrm{MPa}$ to $182 \mathrm{Mpa}$; thus samples with varied densities could be examined in dropweight tests. The size of prepared samples was $\emptyset 10 \mathrm{~mm} \times$ $15 \mathrm{~mm}$ (Figure 2(a)) and $\emptyset 10 \mathrm{~mm} \times 3 \mathrm{~mm}$ for drop-weight tests (Figure 1(a)).

Drop-weight tests were performed with a fall hammer impact sensitivity tester with a drop mass of $10 \mathrm{~kg}$ and a maximum drop height of $1.5 \mathrm{~m}$. Each test was conducted with the sample placed on the center of an anvil without constraint and directly impacted by the drop mass. A standard Bructon method [8] was adopted to calculate the drop height that would trigger chemical reactions at $50 \%$ possibility; then the ignition energy can be approximated as the potential energy of the drop-weight. High-speed photography with the frame rate up to 6,000 frames/s was used to observe the impact process. During each test, if the camera had captured any flame, the sample was taken as reacted and vice versa.

Quasi-static compression was performed on prepared samples with SFLS-30T electrohydraulic press. During the compression, the sample was placed between two hardened steel anvils (Figure 2(a)) and was compressed at the speed of $10 \mathrm{~mm} / \mathrm{min}$, until the maximum load of $52 \mathrm{kN}$ was reached. All tests were conducted under $25^{\circ} \mathrm{C}$ ambient temperature. Stress-strain curves of all samples were recorded automatically by the hydraulic press.

Al-PTFE samples were characterized by Hitachi S-3400N II scanning electron microscope (SEM) to explore the relation between the material's microstructures and the initiation mechanism.

\section{Results and Discussion}

As shown in Figure 1(b), when Al-PTFE reacted under impact, intensive light was captured by high-speed photography, accompanied with explosion sound. It can be seen from the recovered sample (see Figure 1(c)) that the start of the reaction is near the edge of the sample where shear deformations concentrate most intensively [4]. Then the reaction propagates from the edge to the center of the sample and then quenched, which could be attributed to the quick densification caused by the drop mass, since 


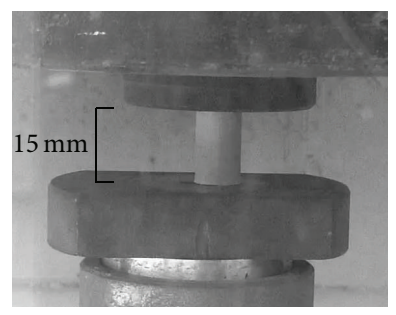

(a)

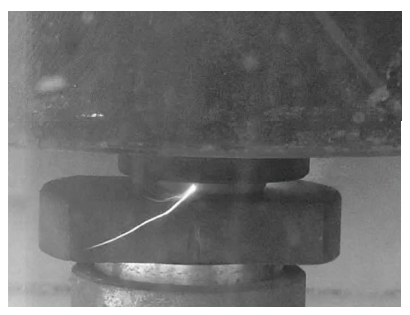

(b)

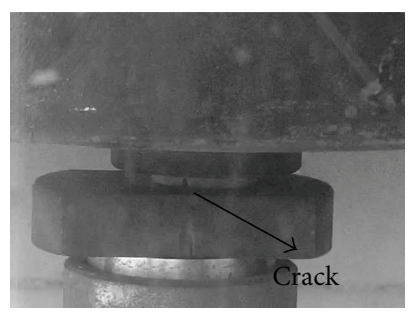

(c)

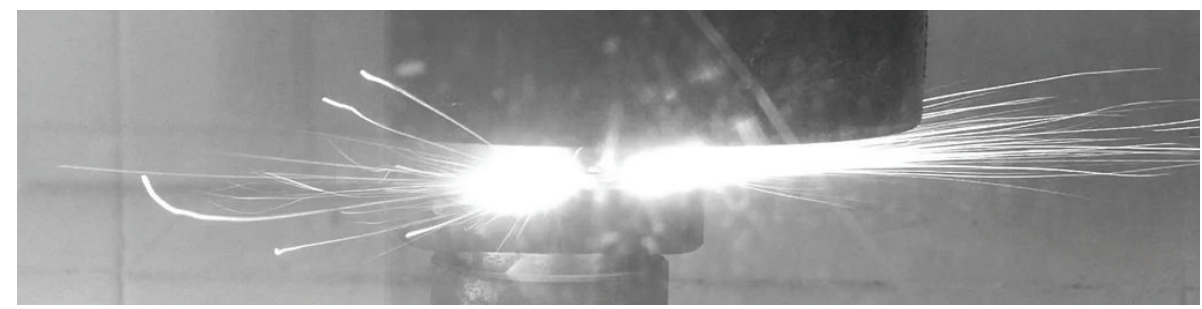

(d)

FIGURE 2: Photograph of Al-PTFE under quasi-static compression. (a) Before compression. (b) First sign of initiation. (c) Crack formed along with the initiation. (d) Violent exothermic reaction.

TABLE 1: Results of quasi-static compression and drop-weight tests.

\begin{tabular}{lcccccc}
\hline $\begin{array}{l}\text { Molding pressure } \\
(\mathrm{Mpa})\end{array}$ & Sintering & $\begin{array}{c}\text { Density } \\
\left(\mathrm{g} / \mathrm{cm}^{3}\right)\end{array}$ & $\begin{array}{c}\text { Elasticity modulus } \\
(\mathrm{MPa})\end{array}$ & $\begin{array}{c}\text { Yield stress } \\
(\mathrm{MPa})\end{array}$ & $\begin{array}{c}\text { Absorbed energy } \\
(\text { static })(\mathrm{J})\end{array}$ & $\begin{array}{c}\text { Absorbed energy } \\
(\mathrm{dynamic})(\mathrm{J})\end{array}$ \\
\hline 72 & Yes & 2.29 & 269 & 19.1 & 103 & 91 \\
108 & Yes & 2.30 & 324 & 19.2 & 100 & 89 \\
182 & Yes & 2.31 & 336 & 19.6 & 88 & 78 \\
\hline
\end{tabular}

constrained space would limit further shear deformation of the material in the central region. In comparison, the samples did not undergo initiation (Figure 1(d)) because of insufficient drop height merely flattened by the hammer and deformed uniformly in all directions.

The absorbed energy derived from results of drop-weight tests for sintered Al-PTFE was listed in Table 1. As molding pressure rises from $72 \mathrm{MPa}$ to $180 \mathrm{MPa}$, averagely $15 \%$ less energy is needed to initiate the reaction for sintered Al-PTFE.

Interestingly, it was found that a batch of Al-PTFE samples could initiate during quasi-static compression. Subsequent investigations show that this batch of composites had gone through a different sintering process such that the sintering temperature was accidentally set to a lower temperature $\left(350^{\circ} \mathrm{C}\right)$.

Figure 2 shows the whole process of the initiation phenomenon. As the sample was pressed to 0.8 engineering strain, the first sign of initiation was observed (Figure 2(b)). The shear force is most intense in the vicinity of the outer surface of the cylinder from where initiation started. Multiple experimental results indicate that the formation of brittle cracks was necessary for the initiation (Figure 2(c)). Then violent exothermic reactions consumed the whole sample within 3-4 seconds (Figure 2(d)).

It could be seen from Figure 3 that the main difference between reacted and unreacted samples is the remarkably higher toughness (the area under the stress-strain curve, where stress and strain are engineering stress and engineering strain) of the reacted sample, which means that much more energy was absorbed by the reacted sample before the failure occurs.

To compare the amount of energy absorbed by Al-PTFE during quasi-static compression and dynamic impact, the energy was approximated by calculation for each tested sample. For quasi-static compression, the absorbed energy can be estimated by the work done by the universal testing machine along the compress direction, which can be calculated as

$$
E_{\mathrm{as}} \approx W=\sum F_{t} \Delta s
$$

where $E_{\mathrm{as}}$ is estimated energy absorption for static compression, $W$ is the work done by the testing machine, $F_{t}$ is the transient force, and $\Delta s$ is infinitesimal increases of displacement, where $F_{t}$ and $\Delta s$ can be directly retrieved from the testing machine. For drop-weight test, the absorbed energy was estimated by the potential energy of the drop mass as in

$$
E_{\mathrm{ad}} \approx E_{p}=m g h,
$$

where $E_{\mathrm{ad}}$ is estimated energy absorption for dynamic compression, $E_{p}$ is the potential energy of the drop mass, $m$ is the mass of the drop mass, and $h$ is the drop height. All this information was plotted into Figure 4 and averaged energy absorption was listed in Table 1. 


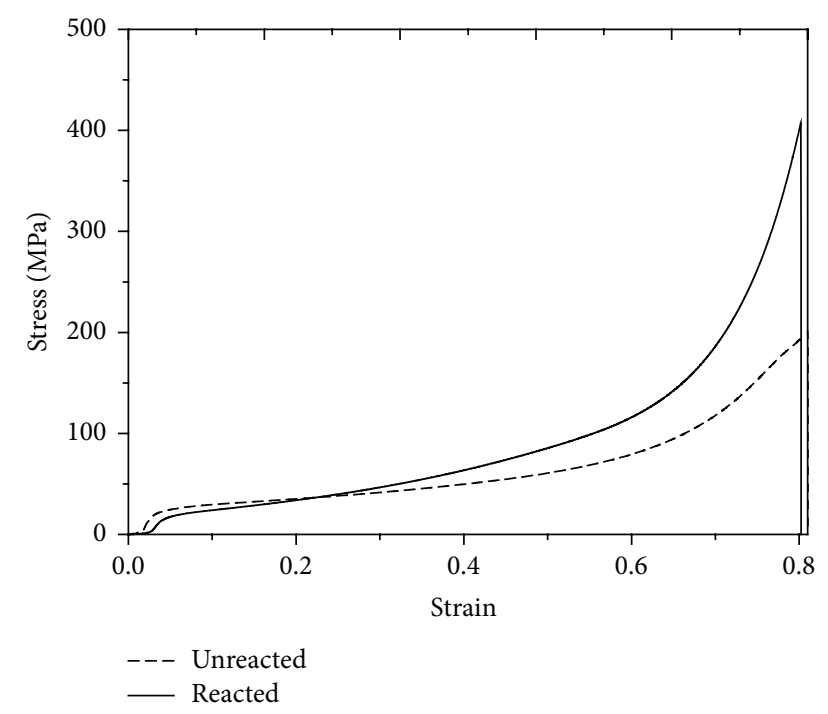

FIGURE 3: Typical stress-strain curves of unreacted and reacted samples, where stress and strain are engineering stress and engineering strain. Al-PTFE under quasi-static compression, which shows that reacted sample has higher toughness (the area under the stressstrain curve) than the unreacted one.

The energy level required for initiation was similar for both quasi-static compression (88-103 J) and dynamic impact (77-91 J); the discrepancy could be further reduced if heat dissipation was taken into consideration, because more heat will dissipate to the surrounding environment through diffusion during the slow process of quasi-static compression while dynamic impact can be treated as adiabatic process. Actually, the initiation sensitivity during quasi-static compression can be represented by the reacted point in Figure 4, since the energy was gradually imparted into the sample.

The observations mentioned above show that the initiation of Al-PTFE under compression could happen even when the strain rate is extremely low, which is contradictory to the generally believed view that only the mechanical work of a high-strain-rate plastic deformation process is enough to provide the energy required to drive the reaction [4]. Furthermore, it seems that the initiation of Al-PTFE under compression may be insensitive to the rate of imported energy. If the speculation is true, then the energy absorption may be a better criterion for Al-PTFE initiation than stress or impact speed.

It was found that the average density of samples which could initiate under quasi-static compression was $2.25 \mathrm{~g} / \mathrm{cm}^{3}$ and that of the samples that could not initiate was $2.30 \mathrm{~g} / \mathrm{cm}^{3}$. The different density should be attributed to different crystallinities of PTFE matrixes. The crystallinity $X_{c}$ of PTFE could be estimated by

$$
X_{c}=\frac{\rho_{c}}{\rho} \frac{\rho-\rho_{a}}{\rho_{c}-\rho_{a}}
$$

where $\rho$ is the measured density for PTFE of unknown crystallinity and $\rho_{c}$ and $\rho_{a}$ are density values of pure crystalline PTFE and pure amorphous PTFE separately. The calculation

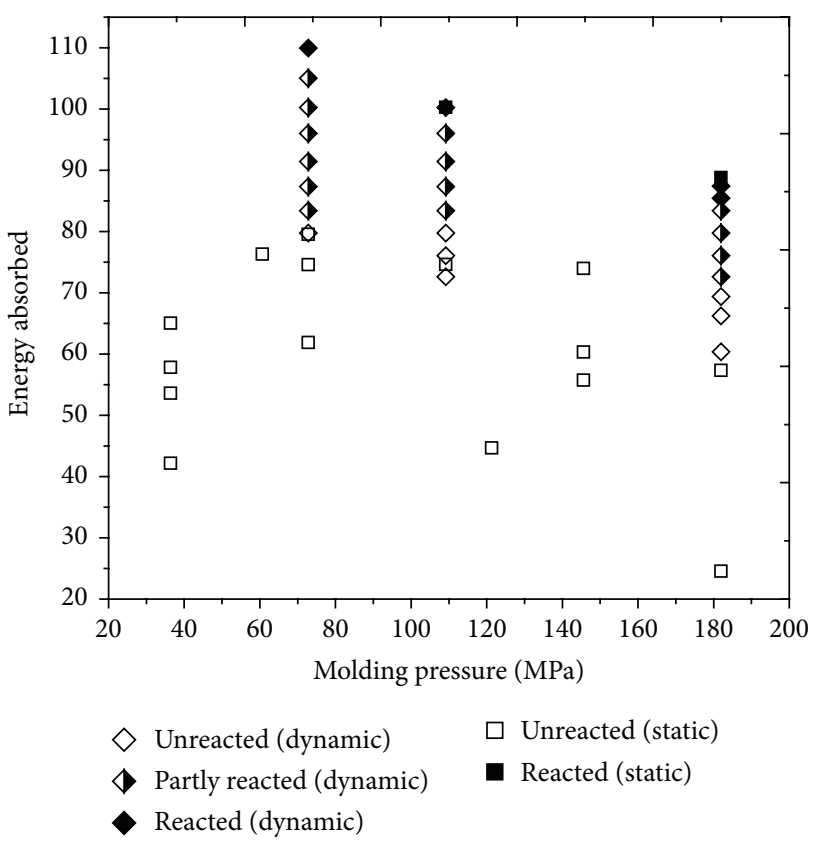

FIgURE 4: Energy absorption for Al-PTFE under quasi-static and dynamic compression. For static compression, each unreacted point represents the result of a single sample; each reacted point means the lowest energy level needed to initiate. For dynamic compression, an unreacted point means no reaction has been observed at that energy level; a partly reacted point means reaction was observed for at least one sample; a reacted point means all samples were reacted at that energy level. Notice that at energy of $100 \mathrm{~J}$ both reactions under static compression and under dynamic compression took place, which made the point look like an eight-pointed star.

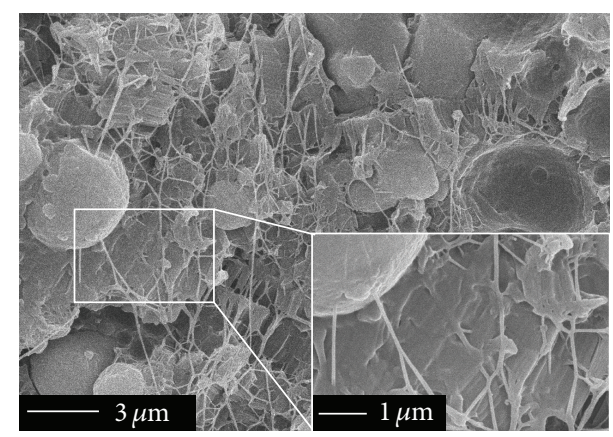

FIGURE 5: SEM image of the microstructure of unreacted Al-PTFE.

shows that unreacted Al-PTFE has higher crystallinity (63\%) than that of reacted Al-PTFE (43\%). The lower crystallinity explains the higher toughness of the reacted composite, because PTFE molecular chains in amorphous regions are entangled and twisted together, which hinders molecular motion. This was confirmed by SEM images. In Figure 5, the surface of unreacted PTFE matrix was smooth because of ordered arrangements of molecular chains. On the contrary, the reacted PTFE matrix in Figure 6 was coarse and full of entanglement. 


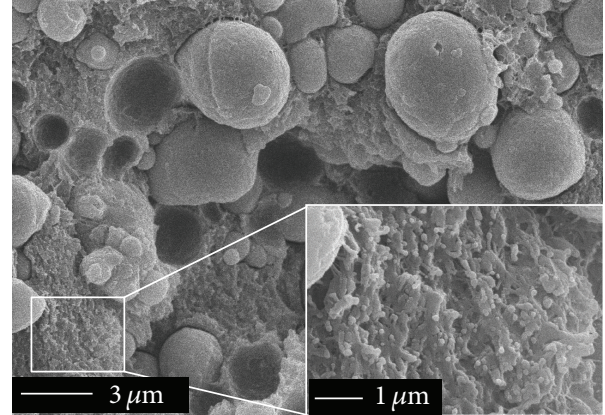

FIGURE 6: SEM image of the microstructure of reacted Al-PTFE.

We also observed numerous PTFE fibrils in unreacted composites (Figure 5), which were absent in reacted composites (Figure 6). Brown and Dattelbaum [9] thought that PTFE fibrils nucleate from a point of stress concentration and form in the principle stress direction. Kitamura et al. [10] reported that fibril formation is a process of unraveling of the crystalline domains to form an oriented ribbon-like crystalline structure in the direction of loading. Although the precise formation mechanism of fibrils is still not fully understood, our experiments results indicate that the growth of fibrils is more favored in high crystallinity regions. Fibrils have been shown to provide a mechanism to dissipate energy [11] and stabilize a crack tip by bridging [12, 13]. As the fibrils bridge the crack plane, they blunt the crack and shield the material ahead of the crack, preventing rapid crack propagation [9]. Thus, unreacted composites were hard to crack and initiate, since the formation of cracks was observed as a prerequisite condition of initiation.

To understand the mechanism behind ignition of $\mathrm{Al}-$ PTFE under quasi-static compression, further experiments should be conducted. To determine the influence of mechanisms based on heat accumulation and diffusion, such as hot-spot theory and melt-dispersion mechanism [14], high temperature calorimetric systems including thermocouples and/or imaging spectrometers should be adopted. To verify the influence of mechanisms based on mechanical interaction induced intimate mixing of constituents, such as ROLLER model [15] and particle velocity dispersion (PVD) model [16], the microscopy for recovered sample just before reaction should be conducted, while numerical simulations would also contribute to the further understanding of the stress distribution in the sample.

\section{Conclusions}

In conclusion, we compared the initiation phenomenon of Al-PTFE in quasi-static compression and in drop-weight test. Quasi-static tests suggest that reacted Al-PTFE samples had much higher toughness than unreacted samples. Dynamic test showed that the energy level needed to initiate the material was similar for quasi-static compression (88-100 J) and dynamic impact (77-91J). The difference in density indicates that unreacted Al-PTFE has a higher crystallinity, which leads to the lower toughness. The SEM images show numerous PTFE fibrils in unreacted composites which made the sample harder to crack and initiate.

\section{Conflict of Interests}

The authors declare that there is no conflict of interests regarding the publication of this paper.

\section{Acknowledgments}

The research was sponsored by the National Basic Research Program of China (2011CB610305) and The Open Project of State Key Laboratory (DPMEIKF2013-06).

\section{References}

[1] E. M. Hunt, S. Malcolm, M. L. Pantoya, and F. Davis, "Impact ignition of nano and micron composite energetic materials," International Journal of Impact Engineering, vol. 36, no. 6, pp. 842-846, 2009.

[2] R. Ames, "Vented chamber calorimetry for impact-initiated energetic materials," in Proceedings of the 43rd AIAA Aerospace Sciences Meeting and Exhibit, Reno, Nev, USA, January 2005.

[3] R. J. Lee, W. Mock Jr., J. R. Carney et al., "Reactive materials studies," in Proceedings of the Conference of the American Physical Society Topical Group on Shock Compression of Condensed Matter, Shock Compression of Condensed Matter, vol. 845 of AIP Conference Proceedings, pp. 169-174, Baltimore, Md, USA, August 2006.

[4] R. G. Ames, "Energy release characteristics of impact-initiated energetic materials," in Proceedings of the Multifunctional Energetic Materials Multifunctional Energetic Materials, N. N. Thadhani, R. W. Armstrong, A. E. Gash, and W. H. Wilson, Eds., vol. 896, pp. 123-132, Materials Research Society, 2006.

[5] X. F. Zhang, A. S. Shi, L. Qiao, J. Zhang, Y. G. Zhang, and Z. W. Guan, "Experimental study on impact-initiated characters of multifunctional energetic structural materials," Journal of Applied Physics, vol. 113, no. 8, Article ID 083508, 2013.

[6] D. B. Nielson, R. L. Tanner, and G. K. Lund, "High strength reactive materials," Google Patents, 2003.

[7] C. D. Yarrington, Combustion Characterization and Modeling of Novel Energetic Materials: Si/Ptfe/Viton and Al/Ptfe/Viton, ProQuest, UMI Dissertations Publishing, 2011.

[8] United Nations, Recommendations on the Transport of Dangerous Goods: Manual of Tests and Criteria, United Nations, New York, NY, USA, 1995.

[9] E. N. Brown and D. M. Dattelbaum, "The role of crystalline phase on fracture and microstructure evolution of polytetrafluoroethylene (PTFE)," Polymer, vol. 46, no. 9, pp. 3056-3068, 2005.

[10] T. Kitamura, S. Okabe, M. Tanigaki, K.-I. Kurumada, M. Ohshima, and S.-I. Kanazawa, "Morphology change in polytetrafluoroethylene (PTFE), porous membrane caused by heat treatment," Polymer Engineering \& Science, vol. 40, no. 3, pp. 809-817, 2000.

[11] M. Jie, C. Y. Tang, Y. P. Li, and C. C. Li, "Damage evolution and energy dissipation of polymers with crazes," Theoretical and Applied Fracture Mechanics, vol. 28, no. 3, pp. 165-174, 1998.

[12] R. Marissen, “Craze growth mechanics," Polymer, vol. 41, no. 3, pp. 1119-1129, 2000. 
[13] B. N. Sun and C. C. Hsiao, "Nonlinear quasi-fracture behavior of polymers," Journal of Applied Physics, vol. 57, no. 2, pp. 170174, 1985.

[14] V. I. Levitas, "Mechanochemical mechanism for reaction of aluminium nano- and micrometre-scale particles," Philosophical Transactions of the Royal Society A: Mathematical, Physical and Engineering Sciences, vol. 371, no. 2003, Article ID 20120215, pp. 1-8, 2013.

[15] A. N. Dremin and O. N. Breusov, "Processes occurring in solids under the action of powerful shock waves," Russian Chemical Reviews, vol. 37, no. 5, pp. 392-402, 1968.

[16] S. S. Batsanov, G. S. Doronin, S. V. Klochkov, and A. I. Teut, "Synthesis reactions behind shock fronts," Combustion, Explosion, and Shock Waves, vol. 22, no. 6, pp. 765-768, 1986. 

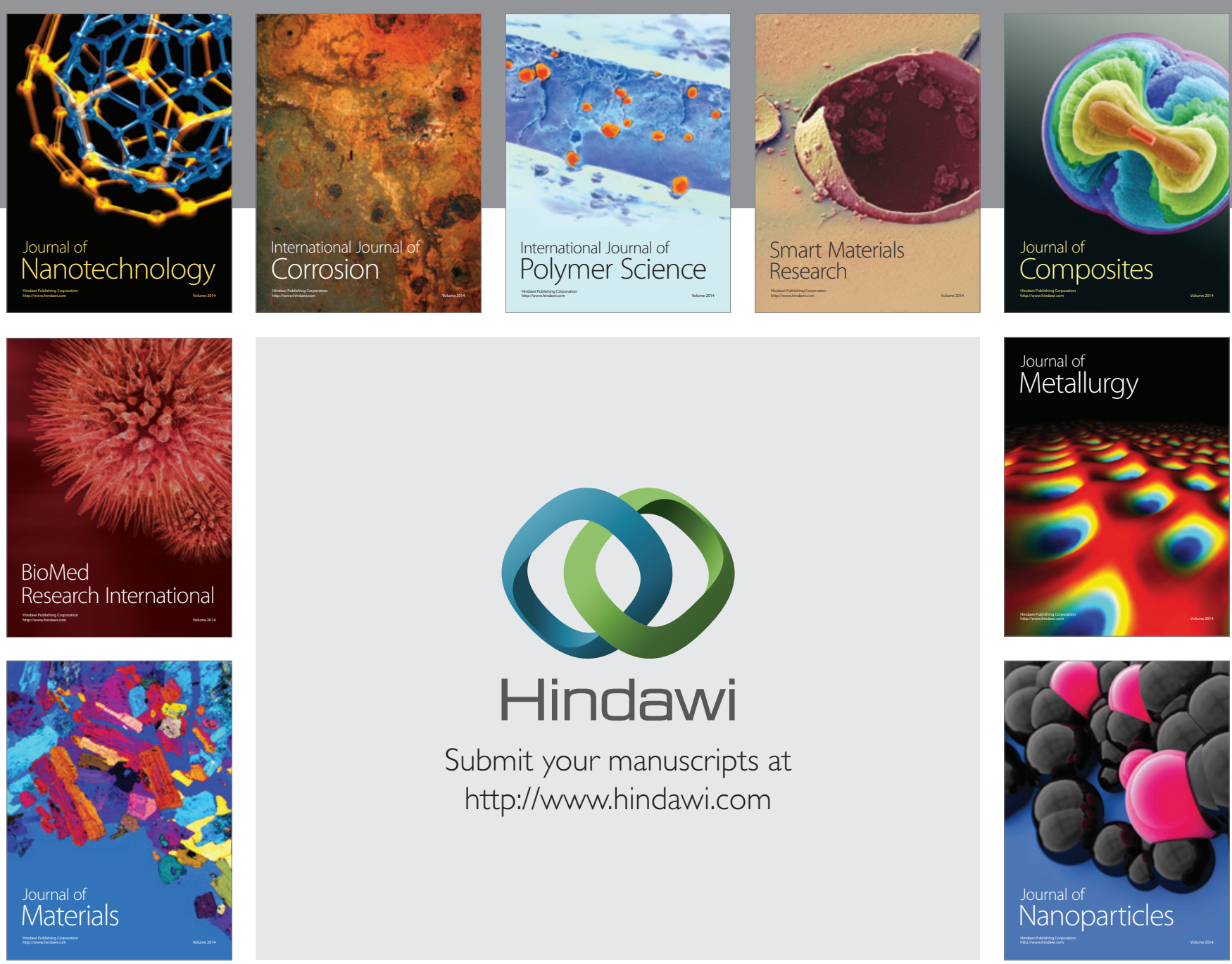

Submit your manuscripts at http://www.hindawi.com
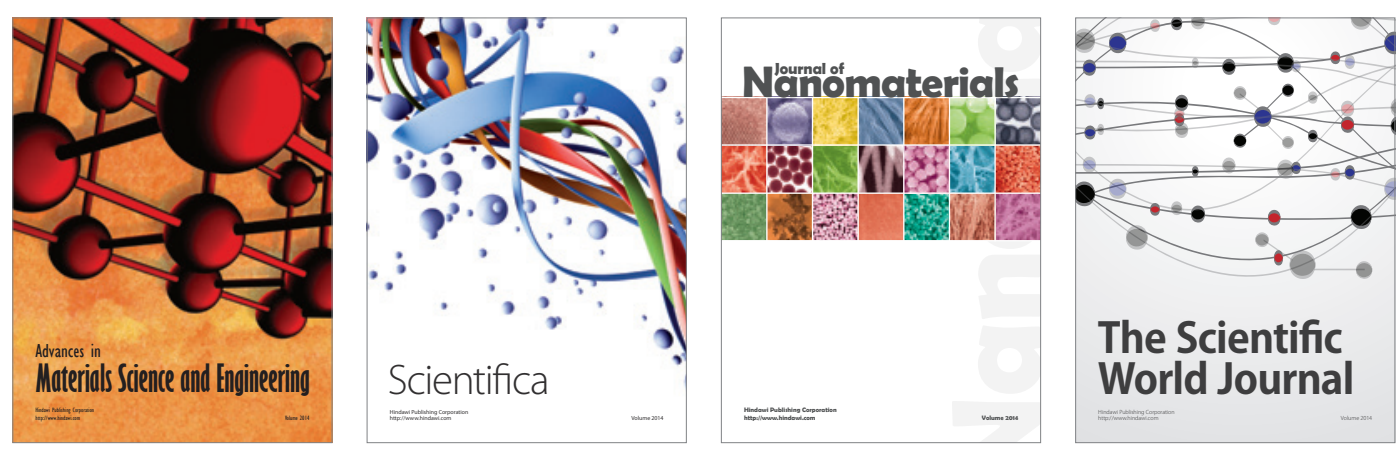

\section{The Scientific World Journal}
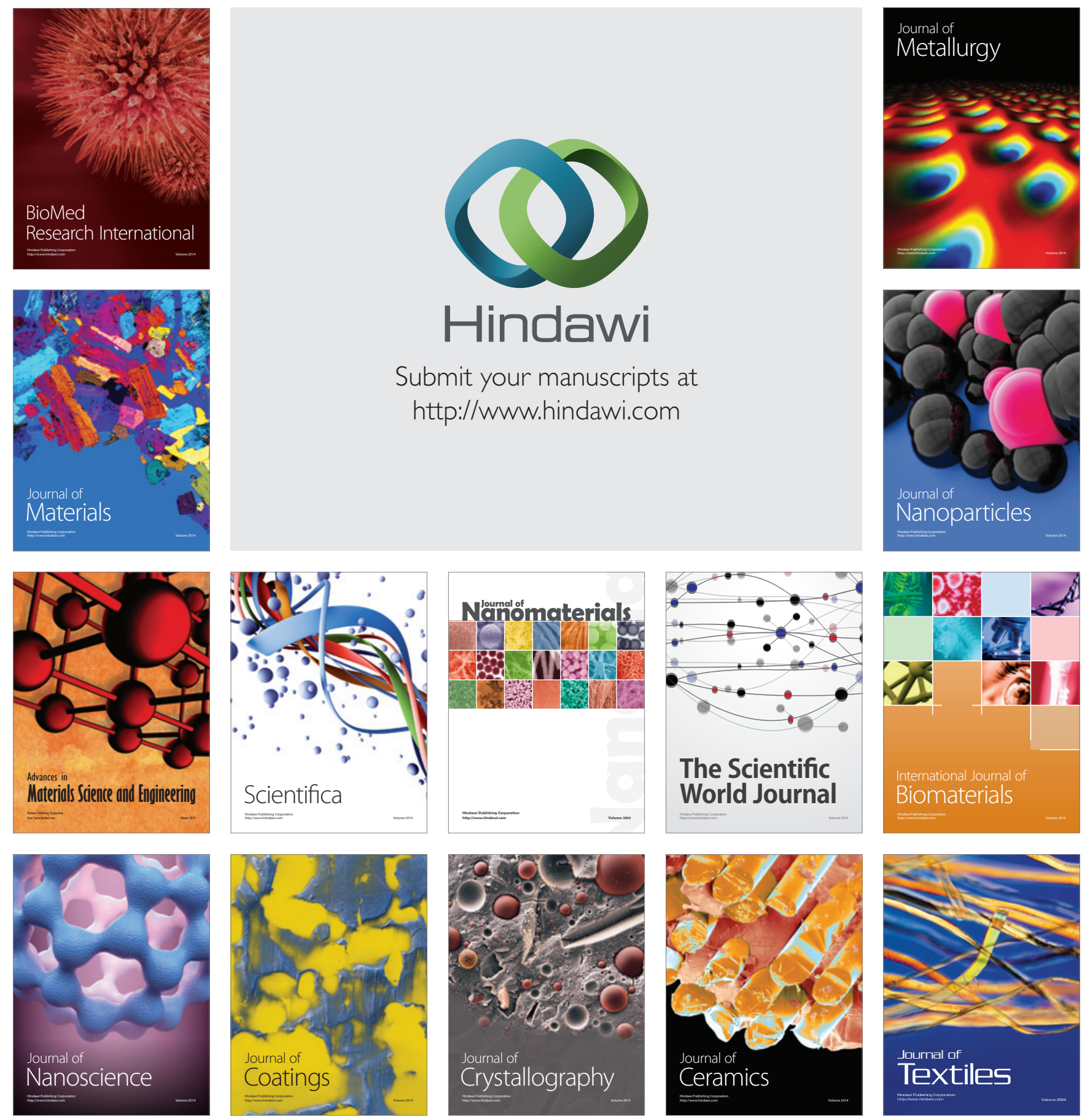